RU Тезаурусное моделирование английской терминологии типологии текста (на примере семантического поля термина "text type")

\author{
Жучкова И. И.
}

\begin{abstract}
Аннотация. Цель исследования заключается в систематизации английской типологии текста и ее терминов с помощью тезаурусного подхода, предполагающего конструирование семантических полей и выявление информационно-семиотической природы изучаемой терминологии. Научная новизна исследования состоит в том, что на материале английского языка была построена тезаурусная модель англоязычной типологии текста. В результате исследования было сконструировано семантическое поле термина “text type” с наглядной схемой семантических отношений, объединяющих терминологию английской типологии текста в единую систему.
\end{abstract}

\title{
Thesaurus Modeling of English Text Typology Terminology (By the Example of the Term "Text Type")
}

\section{Zhuchkova I. I.}

\begin{abstract}
The research objective includes systematization of English text typology terminology on the basis of thesaurus approach which involves constructing semantic fields and identifying informational-semiotic nature of terminology under study. Scientific originality of the paper lies in the fact that the researcher proposes thesaurus model of English text typology terminology. The research findings are as follows: the author develops semantic field of the term "text type", explicates its semantic relations that constitute the system of English text typology terms.
\end{abstract}

\section{Введение}

Классификация текстов «важна как для изучения текстовой деятельности, определения специфики текста и его качеств, так и для обучения порождению текстов и их интерпретации в образовательной сфере» [1, с. 291]. В 70-80-х годах прошлого века типологическая единица анализа выделялась, исходя из внутритекстовых критериев (то есть с опорой только на внутренние особенности текстов). Принимая во внимание тот факт, что подобная типология не может быть полной, ведь тексты состоят не только из лексических элементов, ученые вскоре стали делать акцент на экстралингвистический фактор. При анализе текстов стали учитываться, например, обстоятельства коммуникации, характер партнеров, взаимоотношения между ними, их фоновые знания и коммуникативная интенция. Как справедливо замечает В. Е. Чернявская, «все дальнейшие попытки совместить интра- и экстралингвистические признаки как классифицирующую основу приводили к разного рода взаимоналожениям и противоречиям» $[10$, с. 51$]$.

Актуальность данного исследования обусловлена тем, что типология текстов, несмотря на свое центральное положение в англоязычной лингвистике текста, разработана недостаточно. Это связано с многоаспектностью и сложностью самого феномена текста, что обуславливает проблему отсутствия общих критериев, положенных в основу различных классификаций текстов. Отсутствие единых терминов для классификации текстов представляет еще одну проблему в данной области научного знания. Расхождения в терминологии возникают при сопоставлении русскоязычной терминологии с общепринятыми терминами в этой области, используемыми англоязычными авторами. Данная ситуация может быть объяснена тем, что «выделение определенных критериев для классификации текстов связано с различными исследовательскими подходами, принятыми за основу... Все это приводит к сложностям с пониманием различных типологий и порождает определенные проблемы при выработке единых интернациональных терминов, обозначающих различные типы текстов» [5, c. 126]. 
Объектом исследования является английская терминология предметной сферы «типология текста». Предметом исследования выступает информационно-семиотическая природа английской терминологии типологии текста, выявляемая на основе тезаурусного подхода.

Для выявления информационно-семиотической природы английской терминологии типологии текста в настоящем исследовании были поставлены следующие задачи:

- обосновать выбор информационно-семиотического подхода в качестве основы настоящего исследования;

- описать технологию построения тезауруса английских терминов типологии текста;

- построить семантическое поле для заглавного термина text type (тun текста), отражающее разнообразные семантические связи, объединяющие английскую терминологию типологии текста в единую систему.

Для решения поставленных задач в работе применены следующие методы исследования: сравнительный анализ определений терминов из современных англоязычных источников, метод компонентного анализа словарных дефиниций термина, способствующий выявлению минимальных компонентов значения термина, а также тезаурусный метод, позволяющий смоделировать семантическое поле заглавного термина.

Основную теоретическую базу исследования составили работы Р. Г. Пиотровского [8], Н. Ю. Зайцевой, А. В. Ивкиной [6; 7], А. Ф. Абдуллиной [7], Ю. И. Горбунова [3], Е. Ю. Горбунова [2], придерживающихся информационно-семиотического подхода в исследовании терминологии, а также работы зарубежных лингвистов Т. А. ван Дейка [15], Т. Виртанена [19], Р. дэ Богранда, В. У. Дресслера [11], А. Тросборг [18], занимающихся изучением различных классификаций текста.

Практическая значимость исследования состоит в том, что опыт тезаурусного моделирования дает возможность создать такой тип тезауруса, который как комплекс лингвистических знаний может стать вспомогательным средством для глубокого изучения и усвоения английской терминологии типологии текста в процессе профессиональной подготовки лингвистов.

\section{Основная часть}

Для решения поставленных выше задач нами был выбран семиотический подход к изучению терминологии, в котором термин рассматривается как языковой знак в смысле Ф. де Соссюра [9]. Данный подход был выбран в качестве ключевого по причине того, что термин в пределах информационно-семиотической теории рассматривается как двойственный языковой знак, как психическая сущность, которая имеет означаемое и означающее. Означаемое терминологического знака имеет сложное строение. Оно состоит из двух компонентов: денотат (целостный образ референта) и десигнат (понятийно-классифицирующий компонент знака) [8].

Одним из выдающихся российских деятелей, работавших в русле данной теории, является профессор Р. Г. Пиотровский. Он полагает, что «термин» следует определять как «элементарный, составной или усложненный знак, который, выступая в рамках конкретной научно-деловой коммуникации, воплощает в своем означаемом понятие, относящееся к определенной предметной области науки, техники, а также культурной, административной или политической деятельности» [Там же, с. 69].

Исходя из основной задачи научно-делового общения, которая заключается в точном, недвусмысленном и систематизированном изложении научной, административной, политической и профессиональнотехнической информации, наибольшую ценность, с точки зрения Р. Г. Пиотровского, представляет семантическая значимость, указывающая место десигната в системе понятий (семантическом поле) соответствующей предметной области, включение в которую является необходимым условием для того, чтобы слово стало термином [Там же, с. 28-30].

Своеобразие термина, таким образом, следует искать, в основном, в соотношении классификационноабстрагирующей способности десигната, с одной стороны, и денотата как целостного образа реального объекта, с другой стороны, что, в свою очередь, позволяет четко определять место термина в тезаурусе и выделять наиболее важные семы значения. Таким образом, конструирование семантического пространства англоязычных терминов типологии теста с помощью тезаурусного подхода позволяет связать исследуемые термины в единую семиотическую систему.

Тезаурусный подход к моделированию терминологии предполагает прохождение нескольких этапов, таких как выбор источников для поиска материала исследования, выбор метода для анализа дефиниций терминов, выделение семантических отношений, конструирование семантического поля.

Проблема отбора словарных единиц в тезаурус «может быть решена путем обращения к корпусу научнолингвистических текстов, включающему в себя лингвистические словари, учебную литературу, монографии, а также научные статьи» [5, с. 65]. Основным критерием при выборе научно-лингвистических текстов является тот факт, что они должны быть написаны на английском языке и опубликованы в англоязычных странах. Во всех вышеперечисленных источниках особое внимание уделяется определениям или дефинициям терминов, поскольку в словарных дефинициях заключены те признаки, из которых строится значение слова. Для данного исследования были использованы следующие специализированные англоязычные словари: «A Dictionary of Linguistics and Phonetics» [14], «The Concise Oxford Dictionary of Linguistics» [16], а также словари общей тематики: Cambridge Dictionary [12], Merriam-Webster [17], Collins Dictionary [13].

Одним из методов исследования, позволившим выявить значение термина, является компонентный анализ дефиниций терминов. Поскольку «определения терминов выступают в виде набора его семантических признаков» [5, с. 71], метод компонентного анализа позволяет сравнить значения терминов одинаковых и разных 
уровней иерархии, а также выявить минимальные диагностические компоненты или семы значения изучаемого понятия. Данные семы значения помогают отличить значение одного термина от значения других терминов исследуемой сферы. С помощью выделенных нами семантических компонентов значения термина становится возможным определить место, занимаемое десигнатом термина в семантическом поле, и тем самым связать изучаемую терминологию в единую систему.

В работе Ю. И. Горбунова и О. Ю. Горбуновой отмечается, что семантические отношения не только связывают терминологию в единую семиотическую систему как значимостные характеристики, но и составляют структуру исследуемой области знания [4, с. 260]. В ходе исследования англоязычной терминологии типологии текста нами были выявлены семантические отношения разных уровней иерархии, а именно гиперо-гипонимические и меронимические отношения, а также отношения синонимии, эквонимии (ко-гипонимии) и вариантности. Отношения гиперо-гипонимии и меронимии представляют собой связи, объединяющие термины разного уровня иерархии, а отношения синонимии, эквонимии и вариантности связывают термины, находящиеся на одном уровне. Благодаря обширной сети семантических отношений любой термин в конструируемом семантическом поле обладает присущей ему семантической значимостью и является неотъемлемой частью семантического целого.

Следующим этапом в конструировании тезаурусной модели англоязычной типологии текста является построение семантического поля заглавного термина (см. Рисунок 1). Начинать построение семантического поля, призванного систематизировать терминологию различных англоязычных классификаций текстов, следует с термина text type (тип текста), наиболее часто употребляемого для обозначения типологической единицы анализа.

Поскольку классификации текста изучаются таким разделом лингвистики, как лингвистика текста, мы приходим к выводу, что термин text linguistics (лингвистика текста) является голонимом термина text type (тип текста). Стоит обратить внимание и на тот факт, что в лингвистике текста существует отдельный раздел, занимающийся исследованиями классификаций текстов. Этот раздел лингвистики называется термином text typology (типология текста). По аналогии, термин text type (тип текста) объединяет отношение меронимии с термином text typology, имеющим, в свою очередь, полный синоним - термин text classification (класcификации текста). Последний из вышеупомянутых терминов связан отношением позиционной вариантности с термином classification of texts (классификации текста).

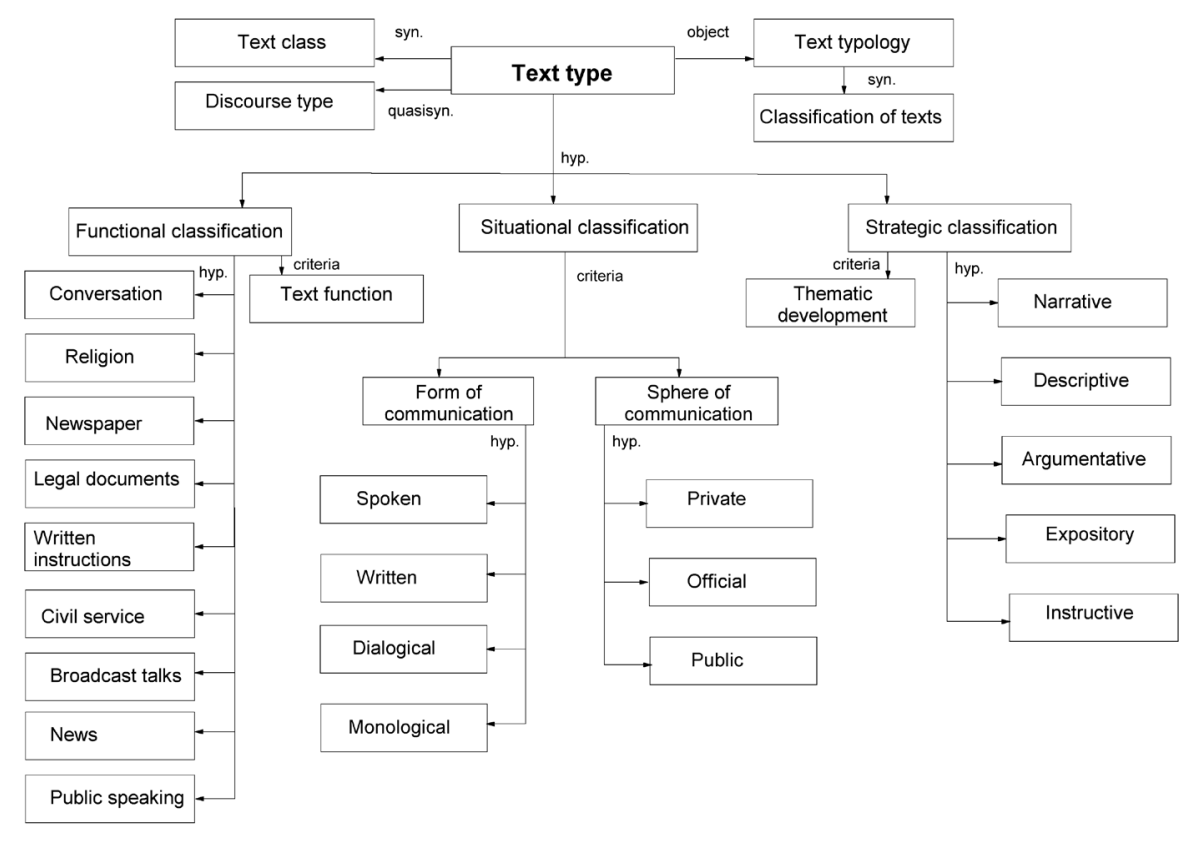

Рисунок 1. Семантическое поле термина tехt tyре (тип текста)

Нельзя обойти вниманием тот факт, что термин text type (тип текста) имеет неоднозначное толкование в работах англоязычных авторов по лингвистике текста. Так, под данным термином может пониматься “а set of heuristics for producing, predicting and processing textual occurrences” [14, p. 186]. / «набор алгоритмов для производства, оценки и обработки текстуальных примеров» (Здесь и далее перевод автора статьи. - И. Ж.). В этом случае термин text type характеризуется набором определенных текстообразующих признаков, а за основу типологической классификации принимается «путь “снизу вверх” - от реально существующих текстов к их объединению на основе общности тех или иных характеристик» [10, с. 52].

Однако в исследованиях А. Тросборг термин text type (тип текста) обозначает «общие типовые когнитивные операции по структурированию текста и основывается на лингвистических критериях» (Ср.: “Техt types may be defined on the basis of cognitive categories... or linguistic criteria” [18, p. 16]). В данном случае основанием для типологизации текстов является «подход “сверху вниз” - от общих параметров к конкретным текстовым реализациям» $[10$, с. 52$]$.

Принимая во внимание тот факт, что термин text type (тип текста) является многозначным, мы посчитали необходимым проанализировать несколько классификаций текста, базирующихся на разных принципах. 
Так, семантическое поле термина text tyре включает три различных классификации типов текста. Все типы текстов в данном поле являются гипонимами термина text type, который выступает в качестве гиперонима или родового понятия по отношению к ним. Названия классификаций обозначаются терминами situational (ситуативная), functional (функциональная), strategic (стратегическая) classifications (классификации).

Необходимо отметить, что в основе упомянутых выше классификаций лежат разные текстуальные и экстратекстуальные факторы. К примеру, основу для выделения типов текста в функциональной классификации (functional classification) составляет коммуникативная функция текста, обозначаемая термином text function. Общеизвестно, что основное назначение текста - служить не только средством общения между людьми, но и средством передачи информации. Следовательно, выходя за «текстуальные» рамки, мы относим функцию текста к экстратекстуальным факторам (text-external criterion).

Возвращаясь к описанию функциональной классификации, мы выделяем в ней такие типы текста, как talk show broadcast (ток-шоу на радио), пеws (новости), academic article (научная статья), nеwspaper (газета), cooking recipe (кулинарный рецепт) и так далее. Перечисленные выше термины состоят в родовидовых отношениях с термином functional classification (функциональная классификация), который выступает в качестве гиперонима по отношению к ним. Необходимо уточнить, что представленный здесь для наглядности список типов текста является далеко не полным и может быть дополнен бесчисленным количеством других гипонимов термина functional classification.

В следующей рассматриваемой классификации, называемой термином situational classification (cumуативная классификация), в качестве основы для выделения типов текста служат два текстуальных критерия (text-internal criteria), а именно форма коммуникации, которая именуется термином form of communication, и сфера коммуникации, обозначаемая термином sphere of communication. В первом случае у термина text (текст) обнаруживаются такие виды, как spoken (устный), written (письменный), dialogical (диалогичный), monological (монологичный). Данные термины по аналогии с предыдущей классификацией выступают в качестве гипонимов к терминам text type (тип текста) и situational classification (ситуативная классификация). Стоит отметить, что между собой все упомянутые выше термины состоят в отношении эквонимии, то есть являются ко-гипонимами.

Исследование второго критерия дифференциации текстов, лежащего в основе ситуативной классификации, обозначаемого термином sphere of communication (сфера коммуникации), позволило нам классифицировать тексты на три вида, а именно public texts (публичные тексты), private texts (частные тексты), official texts (официальные тексты). Данные типы текста также находятся между собой в отношении ко-гипонимии и являются «видовыми» терминами по отношению к заглавному термину конструируемого семантического поля.

В стратегической классификации, именуемой термином strategic classification (cmpатегическая классификация), основным критерием служит thematic development (тематическая прогрессия) или тематическая организация текста. Можно утверждать, что в данной классификации используется текстуальный критерий (text-internal criterion), так как тематическая прогрессия подразумевает определенную последовательность тем в тексте, определяющую особую организацию текстового пространства. В стратегической классификации нами были выявлены следующие типы текста: narration (повествование), description (описание), argumentation (аргументация), ехроsition (изложение), instruction (инструкция). Нельзя обойти вниманием тот факт, что именно стратегическая классификация типов текста является наиболее распространенной как в русскоязычной, так и в англоязычной лингвистике текста.

Итак, исследовав наиболее употребляемые в англоязычной типологии текста термины, мы пришли к заключению, что в англоговорящих странах не существует единой классификации текстов, а имеющиеся классификации отличаются большим разнообразием. Следует отметить, что описанные выше классификации отнюдь не являются единственными в своем роде, ими не исчерпывается описание английской типологии текстов. Более того, помимо рассмотренных выше экстратекстуальных и текстуальных характеристик текста в качестве основных критериев текстовой дифференциации могут выступать и такие факторы, как психологический, логический или информационный. Однако, проводя настоящее исследование, мы не ставили цель описать и систематизировать все известные английские авторские типологии. Настоящее исследование было направлено на выявление разного рода отношений, которые способствуют объединению основных терминов английской типологии текста в единую семантическую сеть.

\section{Заключение}

В результате работы над данной статьей нами были сделаны следующие выводы:

1. Изучение информационно-семиотической концепции Р. Г. Пиотровского показало, что именно семиотическая модель термина выступает в качестве инструмента, раскрывающего детали знакообразования и механизма формирования терминологической системы. Возможность выделения семантических значимостей в десигнате терминологического знака определила выбор данной концепции в качестве основы настоящего исследования.

2. Разработанная в рамках настоящего исследования технология построения тезауруса английских терминов типологии текста подразумевала применение метода компонентного анализа дефиниций, который способствовал выявлению нюансов значения исследуемой терминологии, и использование различных семантических отношений, которые представляют собой единую систему гиперо-гипонимических, меронимических, синонимических, вариативных и эквонимических отношений, четко определяющих место, которое занимает термин в семантическом поле тезауруса.

3. Тезаурусный подход к моделированию терминологии позволил создать лингвистическую модель, представляющую часть английской типологической терминологии в системно-структурированном виде. Было 
доказано, что в данной области научного знания отсутствуют изолированные понятия, и все изученные термины связаны между собой по принципу «от общего к частному» и образуют в целом иерархическую структуру элементов, что, в свою очередь, приводит к появлению большого количества ко-гипонимов.

Перспективы дальнейших исследований видятся нам в использовании тезаурусной модели, полученной в результате исследования, для систематизации других разделов языкознания. Более того, описание терминологии типологии текста посредством описания семантических отношений может быть продолжено в ходе сопоставления терминов из других текстовых классификаций и на материале других языков.

\section{Источники | References}

1. Болотнова Н. С. Филологический анализ текста: учеб. пособие. Изд-е 4-е. М.: Флинта; Наука, 2009.520 с.

2. Горбунов Е. Ю. Технология лингвистического конструирования предметной области «Английская лексикология» // Вестник современных исследований. 2017. № 7-1 (10). С. 146-157.

3. Горбунов Ю. И. Французская лингвистическая терминология и синергетика // Вестник Волжского университета им. В. Н. Татищева. 2018. Т. 2. № 2. С. 26-36.

4. Горбунов Ю. И., Горбунова О. Ю. Лингвистическое конструирование русско-французского автомобильного тезауруса // Актуальные проблемы теоретической и прикладной лингвистики и оптимизация преподавания иностранных языков. К 80-летию профессора Л. И. Корниловой: сборник материалов VI Международной научной конференции (г. Тольятти, 11-12 октября 2018 г.). Тольятти: Тольяттинский государственный университет, 2018. С. 255-261.

5. Жучкова И. И. Тезаурусное моделирование англоязычной лингвистической терминологии: дисс. ... к. филол. н. Самара, 2016. 302 с.

6. Зайцева Н. Ю., Ивкина А. В. Учебный тезаурус как ресурс межкультурного профессионального общения // Языковая личность и эффективная коммуникация в современном поликультурном мире: материалы V Международной научно-практической конференции, посвященной 20-летию основания кафедры теории и практики перевода факультета социокультурных коммуникаций Белорусского государственного университета (г. Минск, 24-25 октября 2019 г.). Минск: Белорусский государственный университет, 2019. С. 287-291.

7. Зайцева Н. Ю., Ивкина А. В., Абдуллина А. Ф. Учебный тезаурус как средство формирования профессионально-ориентированной креативности студентов // Герценовские чтения. Иностранные языки: сборник научных трудов. СПб.: Российский государственный педагогический университет им. А. И. Герцена, 2020. С. 568-571.

8. Пиотровский Р. Г. Лингвистический автомат (в исследовании и непрерывном обучении): учебное пособие. СПб.: Изд-во РГПУ, 1999. 256 с.

9. Соссюр Ф. де. Курс общей лингвистики. Екатеринбург: Издательство Уральского университета, 1999. 432 с.

10. Чернявская В. Е. Лингвистика текста. Поликодовость, интертекстуальность, интердискурсивность: учебное пособие. М.: Директ-Медиа, 2014. 248 с.

11. Beaugrande R. de., Dressler W. U. Introduction to text linguistics. L. - N. Y.: Longman, 1981. 286 p.

12. Cambridge Dictionary Online [Электронный ресурс]. URL: http://dictionary.cambridge.org/ (дата обращения: 19.07.2021).

13. Collins Dictionary [Электронный ресурc]. URL: https://www.collinsdictionary.com (дата обращения: 19.07.2021).

14. Crystal D. A Dictionary of Linguistics and Phonetics. 6th ed. Oxford: Basil Blackwell, 2008. 389 p.

15. Dijk T. A. van. Discourse and Context: a sociocognitive approach. Cambridge: Cambridge University Press, 2008.288 p.

16. Matthews P. H. The Concise Oxford Dictionary of Linguistics. Oxford: Oxford University Press, 2007. 443 p.

17. Merriam-Webster's Online Dictionary [Электронный ресурс]. URL: http://merriam-webster.com/ (дата обращения: 19.07.2021).

18. Trosborg A. Text Typology and Translation. Amsterdam - Philadelphia: John Benjamins Publishing, 1997. 345 p.

19. Virtanen T. Issues of text typology: Narrative - a "basic" type of text? // Text. 1992. Vol. 12. Issue 2. P. 293-310.

\section{Информация об авторах | Author information}

RU Жучкова Ирина Игоревна ${ }^{1}$, к. филол. н.

${ }^{1}$ Ульяновский государственный педагогический университет имени И. Н. Ульянова

EN Zhuchkova Irina Igorevna ${ }^{1}, \mathrm{PhD}$

${ }^{1}$ Ulyanovsk State University of Education

${ }^{1}$ zhuchkova.ii@inbox.ru

\section{Информация о статье | About this article}

Дата поступления рукописи (received): 03.08.2021; опубликовано (published): 30.09.2021.

Ключевые слова (keywords): термин; тезаурус; семантические отношения; классификация текста; тип текста; term; thesaurus; semantic relations; text typology; text type. 